\title{
Mathematical Modelling In Transportation Sciences
}

\author{
Dr. Sumit Agarwal*, Kushal Johari* \\ *Assistant Professor, Invertis University, Bareilly
}

\begin{abstract}
A logistics network consists of suppliers, manufacturing centers, warehouses, distribution centers, and retail outlets as well as channels for the flow of raw materials, work-in-process inventory, and finished products between the facilities. In many cases, the problems of each logistics functions are treated as isolated functions. There are: network design; information flow; transportation; inventory; and warehousing, material handling, and packaging. Whereas, the basis of performance improvement in integrated logistics network is total cost analysis. That is minimizing the total cost of transportation, warehousing, order processing and information, lot quantity, and inventory carrying cost. In this paper, We consider an integrated logistics problem in minimizing the total logistics cost and provide model for logistics network optimization in form of a mathematical programming model. An integrated model of logistics network minimizes total physical distribution costs by simultaneously determining optimal plants and warehouse locations, flows in the resulting network, shipment compositions and shipment frequencies in the network using heuristics methodology. The objective is to optimize the production and distribution plan so as to minimize its total logistics cost.
\end{abstract}

Keywords: Transportation Sciences, Integrated Model, Mathematical Programming, Network Optimization.

\section{Introduction}

Logistics has gone from being a military matter to being one of the key business issues today. The underlying factor to this situation is, in fact, that logistics is a cross-functional subject, cutting across functional boundaries. Logistics is the work required to move and position inventory throughout a chain of participants. From initial purchase of material or component, the system of logistics adds value by moving inventory when it is needed and where it is needed. Materials and components gain value at each step of their change into finished inventory. A basic definition of logistics is as follows:

"Logistics is the process of strategically managing the procurement, movement and storage of materials, parts and finished inventory (and related information flows) through the organization and its marketing channels in such a way that current and future profitability are maximized through the cost-effective fulfillment of orders."

Logistics deals with the planning and control of material flows as well as related information in organizations, and becomes a critical part of supply chain management. Its mission is to get the right materials to the right place at the right time (Ghiani, G. et.al, 2004). Logistics also deals with mobility concepts relating to tangible as well as intangible assets (Beamon, 1998). Logistics activities connect and activate the objects in the supply chain in the form of a logistics network. A logistics network consists of suppliers, manufacturing centers, warehouses, distribution centers, and retail outlets as well as channels for the flow of raw materials, work-in-process inventory, and finished products between the facilities (Simchi-Levi et al., 2000). On the other side, Tavasszy et.al (2003) stated that logistics deals also with the achievement of customer satisfaction at the minimum level of costs. It is a crucial problem in business nowadays due to the high proportion of logistics costs in the costs of goods sold (Bowersox, 1996).

In order to improve the logistics performance, there are several issues that should be encountered (e.g. Bramel, 1997; Bowersox, 1996; Lambert, 1998). Bowersox (1996) addressed 5 major problems as logistics competencies. There are: network design; information flow; transportation; inventory; and warehousing, material handling, and packaging. Many researchers have proposed the quantitative approach to improve and optimize the logistics system performance, such as Geoffrion, A.(1974), Blumenfeld, D.E. et al (1987), Brown, G.G. et al (1987), and Lakhal, S. et.al (2000).

The new approach to the analysis of logistics network and supply chains has been identified, which has proven to be of significant relevance to companies that have adopted it. This approach is based on the integration of different logistics functions into a single optimization model.

In this paper, We consider an integrated logistics problem in minimizing the total logistics cost and provide model for logistics network optimization in form of a mathematical programming model. The major purpose of this paper is to investigate the application of integrated approach in solving the production and distribution-planning problem. 


\section{Model Structure and Formulation}

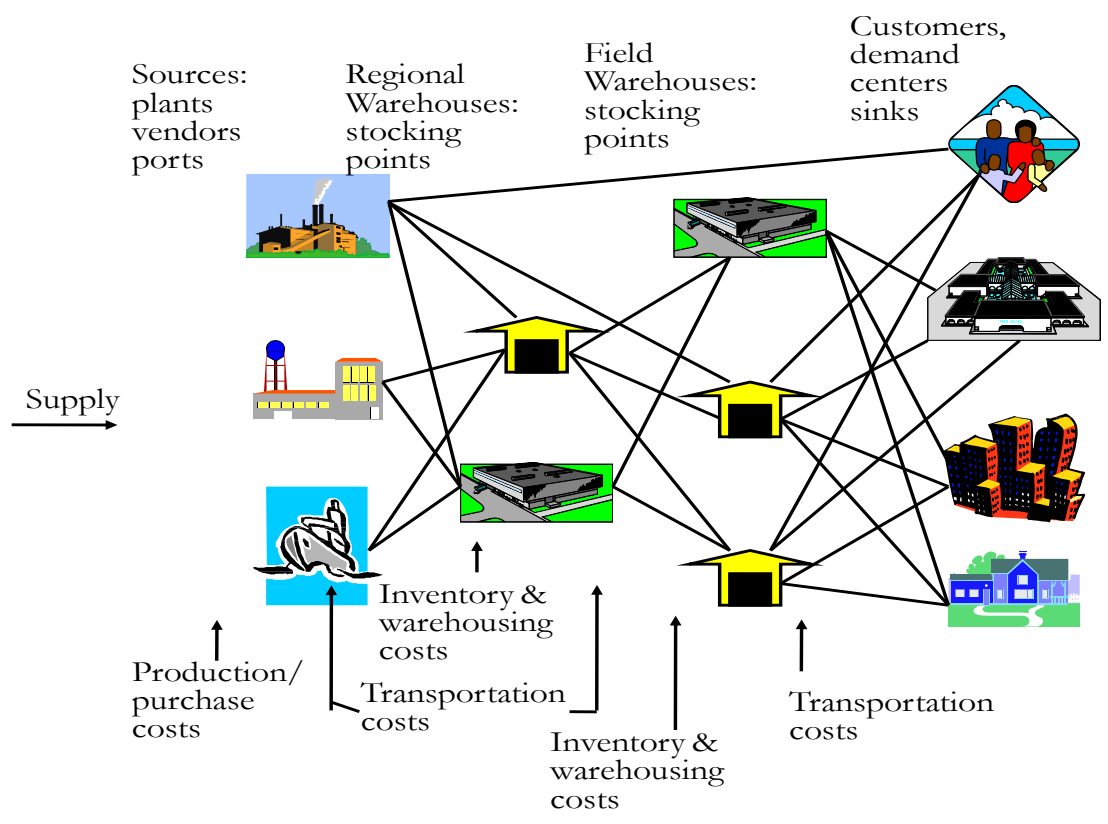

Fig 1. Multi-facilities network flow model

In order to improve logistics network performance, several optimization methods can be used, such as mathematical programming, genetic algorithm, simulated annealing, etc. This paper will use mathematical programming for the reason: it provides insight into problem, its characteristics and the linkages between the various interacting factors. Furthermore, there has been considerable progress in recent years with solving large-scale integer programming problems.

\section{Single- commodity multi-periods multi-facilities system}

In this model (Fig.1), it is assumed that there are a number of plants that produce single product with a specific capacity over period time. The set-up cost is a fixed cost on a lot-for lot basis, not dependent on the realized volume. All products are assumed directly delivered to warehouse or retail outlet. Products are delivered using a fleet homogeneous vehicle. The movement of vehicle is assumed incurs a variable transportation cost only.

The demand for an item in a period at warehouse is expressed as forecasted a real demand. It is assumed that the demands are given and backordering is not allowed. Each warehouse must keep a limited amount of inventory, with higher holding cost.

The objective is to optimize the production and distribution plan so as to minimize its total logistics cost. In this case, the optimization model will be:

Minimize total cost $=$ production cost + transportation cost + inventory cost

Subject to constraints:

- Production capacity,

- Warehouse capacity,

- Material flow requirements,

- Balance constraints of inventory level

We shall represent the problem in the form of network (Fig.2). We define the network for the flow of products from their production points to customers through the warehouse as storage. This model then refers to three components: the production sites, indexed by $i$, the warehouse, indexed by $j$, and the customers, indexed by $k$. 


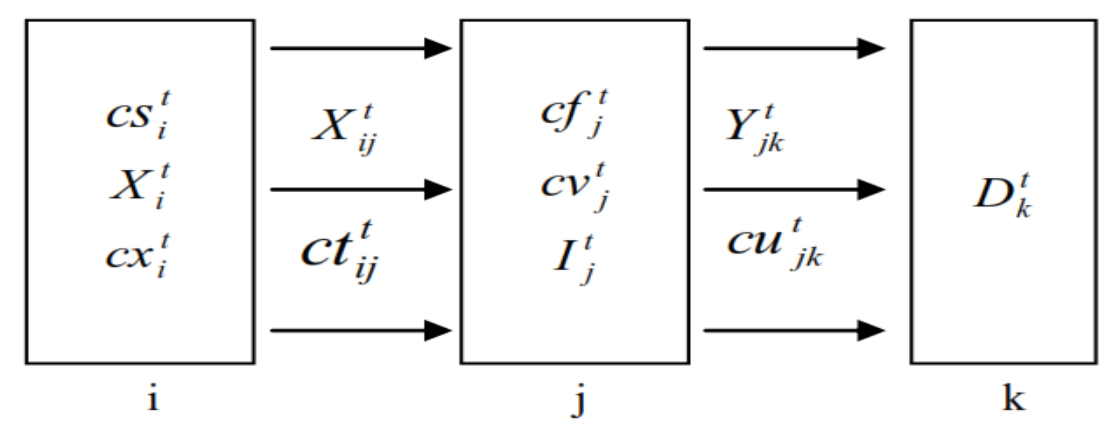

P: Plants W: Warehouses $\quad$ C: Customers

Fig 2. Network Model Representative

A mixed integer model is then developed to solve the problem. The model comprises two cost models: (a) from Plant to Warehouse and (b) from Warehouse to Customers.

Notation that used in the model:

$X_{i}^{t}=$ amount of product produced at plant $\mathrm{i}$ in period $\mathrm{t}$

$X_{i j}^{t}=$ amount of product transported from plant $\mathrm{i}$ to warehouse $\mathrm{j}$ in period $\mathrm{t}$

$Y_{j k}^{t}=$ amount of product transported from warehouse $\mathrm{j}$ to customer $\mathrm{k}$ in period $\mathrm{t}$

$M_{i}=$ capacity of plant $\mathrm{i}$

$W_{j}=$ capacity of warehouse $\mathrm{j}$

$D_{k}^{t}=$ demand of customer $\mathrm{k}$ in period $\mathrm{t}$

$I_{j}^{t}=$ inventory level at warehouse $\mathrm{j}$ at the end of period $\mathrm{t}$

$c s_{i}^{t}=$ setup cost at plant $\mathrm{i}$ in period $\mathrm{t}$

$c x_{i}^{t}=$ unit cost of production at plant $\mathrm{i}$ in period $\mathrm{t}$

$c t_{i j}^{t}=$ unit cost of transportation to delivered product from plant $\mathrm{i}$ to warehouse $\mathrm{j}$ in

Period $\mathrm{t}$

$c u_{j k}^{t}=$ unit cost of transportation to delivered product from warehouse $\mathrm{j}$ to customer $\mathrm{k}$ in

Period $\mathrm{t}$

$c f_{j}^{t}=$ fixed cost at warehouse $\mathrm{j}$ in period $\mathrm{t}$

$c v_{j}^{t}=$ variable cost at warehouse $\mathrm{j}$ in period $\mathrm{t}$

\section{Decision Variable}

$X_{i j}^{t}=$ amount of product transported from plant $\mathrm{i}$ to warehouse $\mathrm{j}$ in period $\mathrm{t}$

$Y_{j k}^{t}=$ amount of product transported from warehouse $\mathrm{j}$ to customer $\mathrm{k}$ in period $\mathrm{t}$

\section{Objective Function}

The objective function (1a-1b) concerns the minimization of costs. It express the total cost includes the cost of production, transportation, and inventory over the time periods. (1a) shows the total cost incurs in stage 1 (from production site until products are delivered to warehouses), and (1b) is the total cost from warehouses to customer side.

$$
\begin{aligned}
& \operatorname{Min} \sum_{i} c s_{i}^{t}+c x_{i}^{t} X_{i}^{t}+\sum_{i} \sum_{j} X_{i j}^{t} c t_{i j}^{t} \\
& +\sum_{j} c f_{j}^{t}+\sum_{j} I_{j}^{t} c v_{j}^{t}+\sum_{j} \sum_{k} Y_{j k}^{t} c u_{j k}^{t}
\end{aligned}
$$

\section{Model Constraints}

$$
\sum_{j} X_{i j}^{t} \leq M_{i}
$$




$$
\begin{array}{ll}
\sum_{i} X_{i j}^{t}+I_{j}^{t-1}-\sum_{k} Y_{j k}^{t} \leq W_{j}^{t} & \forall j, t \quad(3) \\
\sum_{j} X_{i j}^{t} \geq \sum_{k} Y_{j k}^{t} & \forall i, t \\
D_{k}^{t}=\sum_{j} Y_{j k}^{t} & \forall j, t \\
\sum_{i} X_{i j}^{t}+I_{j}^{t-1}=\sum_{k} D_{k}^{t}+I_{j}^{t} & \forall j, t \\
X_{i j}^{t}, Y_{j k}^{t}, I_{j}^{t} \geq 0 & \\
M_{i}, W_{j}^{t} \geq 0 &
\end{array}
$$

From the model, constraints (2) is related to the capacity of production facility. It is also indicate the maximum number of product that can be produced during period $t$ in plant $i$. Product flow from plants to warehouses must respected the throughput capacity of warehouse j, as indicated in (3). Constraint (4) related to product flow requirement in warehouse $\mathrm{j}$. Total product delivered out from warehouse cannot exceed total product delivered to warehouse. Constraint (5) requires that warehouses must satisfy all demand. A Balance constraint of inventory level in warehouse $\mathrm{j}$ is provided by (6). (7) And (8) are non-negative value.

\section{Multi periods issue}

Analysis of multi-period issue is mostly used to anticipate periods of high demand. Therefore, it is necessary to store reasonable amount of product in advance, which in our model, this stock will be in warehouses. In this case, we need arcs between nodes representing a same stock during adjacent periods. The product flows on these arcs are products that stay in stock from one period to the next. As for that, there should be holding costs associated with these flows. Constraints (3) and (6) are used to control inventory flow in warehouses as well as its capacity.

\section{Multi-commodity multi-periods multi-facilities system}

The model exposed in the previous section represent the model for single product. In the real industry application, most company produce not only singles product but many products. Therefore, to cover this problem, our mixed integer linier model will be copied to allow us to minimize total cost in multi-product application. To do this, the product type will be indexed by $\mathrm{m}$ and put in subscript that indicates the product model they are related to. The objective function will become:

$$
\begin{aligned}
& \operatorname{Min} \sum_{i} \sum_{m} c s_{i m}^{t}+c x_{i m}^{t} X_{i m}^{t}+\sum_{i} \sum_{j} \sum_{m} X_{i j m}^{t} c t_{i j m}^{t} \\
& +\sum_{j} \sum_{m} c f_{j m}^{t}+\sum_{j} \sum_{m} I_{j m}^{t} c v_{j m}^{t}+\sum_{j} \sum_{k} \sum_{m} Y_{j k m}^{t} c u_{j k m}^{t}
\end{aligned}
$$

\section{IV.Conclusion}

In this paper, models to deal with single-product multi-facilities multi-periods that used to improve logistics network performance have been presented, as well as multi-products. By this model, we can optimize the network performance by minimizing its total cost, and plan the inventory at warehouses. However, this model cannot be used to get the exact solution for larger problem that is composed with a very large number of lines and customers. Therefore, it may be need to develop heuristics to deal with such larger problems.

\section{References}

[1]. Ambrosino, D., Scutella, M.G., 2005, "Distribution network design: New problems and related models", European Journal of Operational Research, Vol. 165 No. 3, pp. 610-624

[2]. Beamon, B.M., 1998, "Supply Chain Design and Analysis: Models and Methods", International Journal of Production Economics, Vol. 55 No. 3, pp. 281-294.

[3]. Beamon, B.M., 1999, "Measuring Supply Chain Performance”, International Journal of Operations and Production Management, Vol. 19 No. 3, pp. 275-292.

[4]. Blanchard, B.S., Logistics Engineering And Management, 5th Edition Prentice-Hall, Inc., Upper Saddle River, NJ, 1998.

[5]. Blumenfeld, D.E., Burns, L.D., Daganzo, C.F., Frick, M.C., and Hall, R.W., 1987, "Reducing logistics costs at General Motors", Interfaces, Vol. 17 No. 1, pp. 26-47

[6]. Bowersox,D.J., Closs, D.J., Logistical Management: The Integrated Supply Chain Process, 1st edition, The McGraw-Hill Companies, 1996.

[7]. Bramel, J., Simchi-Levi, D, The logic of logistics, Springer Series in Operation Research, Springer, 1997. 
[8]. Brown, G.G., Graves, G.W., Honczarenko, M.D., 1987, "Design and operation of a multi -commodity production/distribution system using primal goal decomposition”, Management Science, Vol. 33 No. 11, pp. 1469-1480

[9]. Erenguc, S,S, Simpson, N.C., Vakharia, A.J., 1999, "Integrated production-distribution planning in supply chain: an invited review", European journal of operation research Vol. 115 No. 2, pp. 219-236.

[10]. Flipo, C.D., Finke, G, 2001, “An Integrated model for industrial production-distribution problem”, IEE Transactions, Vol. 33 No. 9 , pp. 705-715.

[11]. Geoffrion, A.M., Graves, G.W., 1974, "Multi commodity distribution system design by benders decomposition", Management Science, Vol. 20, No. 5, pp. 822-844

[12]. Ghiani, G, Laporte, G, and Musmanno, R, Introduction to Logistics Systems Planning and Control, JohnWiley \& Sons, Ltd., 2004.

[13]. Goetschalckx, M., Vidal, C.J., Doganc, K., 2002, "Modeling and design of global logistics systems: A review of integrated strategic and tactical models and design algorithms", European Journal of Operational Research, Vol. 143, Issue 1, 1-13.

[14]. Lei, L., Liu, S., Ruszczynski, A., Park, S., 2003, "On the integrated production, inventory, and distribution routing problem", Research report, RUTCOR.

[15]. Lakhal, S., Martel, A., Kettani, O., Oral, M., 2001, “On the optimization of supply chain networking decisions”, European Journal of Operation Research Vol. 129 No. 2, pp. 259-270.

[16]. Lambert, D.M., Stock, J.R., Strategic Logistics Management, 3rd edition, Irwin, 1993.

[17]. Lambert, D.M., Stock, J.R., Ellram, L.M., Fundamental of Logistics Management, Irwin/McGraw-Hill, 1998.

[18]. Lee, H. L., 2000, "Creating Value Through Supply Chain Integration", Supply Chain Management Review, http://www.manufacturing.net/scm/article/CA151843.html 